\title{
Pregnancy, labor and delivery post spinal cord injury
}

\author{
Leland L Cross MD MPH, Jay M Meythaler JD MD, Stephen M Tuel MS MD, Audrey \\ L Cross RN BA
}

Department of Physical Medicine and Rehabilitation, University of Virginia, Charlottesville, Virginia 22908, USA.

There are approximately 3,000 women of childbearing age who become spinal cord injured each year in the United States. There are few reports in the literature that address pregnancy, labor and delivery in this patient population. We are reporting on 22 women post spinal cord injury who had 33 pregnancies. There were equal numbers of paraplegic and quadriplegic women. Three pregnancies aborted, one spontaneously. The babies were near normal or normal weight with one exception. The mothers waited 5 years on average to become pregnant. Cesarean section was performed on $43 \%$ of pregnancies. Abnormal presentations occurred in over $10 \%$ of pregnancies. Indications for cesarean section included 5 that were repeats; the remainder were necessary due to bleeding (1), breech presentation (1), transverse presentation (2), lack of progress (2), onset of labor 1 day post spinal fusion, and a mother's request to have tubal ligation. Epidural anesthesia was selected for 9 deliveries; 6 of these patients had controlled autonomic hyperreflexia. Five general and 4 local anesthetics were used, and 12 patients received no anesthesia. Diagnostic ultrasound and amniocentesis were used selectively. Complications included autonomic hyperreflexia (9), frequent urinary tract infections, infected pressure sores $(3,2$ resulting in below-knee amputations), seizures during and after delivery, pneumonia, bladder stones (2), episiotomy dehiscence (1), and breakdown of spinal fusion. The newborns were healthy, although one double footling breech vaginal delivery had an APGAR of 1 at $1 \mathrm{~min}, 7$ at $5 \mathrm{~min}$ and 9 at $10 \mathrm{~min}$. One premature baby, who weighed only $1600 \mathrm{~g}$, was a precipitate birth at home unattended. Implications for the care of pregnant SCI women are discussed.

Keywords: spinal cord injury; pregnancy; autonomic hyperreflexia; cesarean section.

\section{Introduction}

There is very little scientific information concerning pregnant women with spinal cord injuries (SCI). A few reports are available summarizing several patients' experiences. ${ }^{1-4}$ Robertson and Guttmann in $1963^{1}$ reported on 28 pregnancies in spinal cord dysfunctional patients: 19 were traumatic SCI and nine were non traumatic, including 5 post polio patients 3 who had transverse myelitis and one spinal cord cyst.

It is now 28 years after that report. Much has changed in obstetrical care and we know a great deal more about SCI care. The problems of pregnancy and of SCI women have not changed as much as has our ability to relate to them. Integrating the advances in these two areas of knowledge and experience while applying current technology will improve the outcomes of patient care for both mother and newborn.

This paper will identify and discuss SCI women who have become pregnant and the outcomes, along with some of the problems encoutered.

\section{Materials and methods}

Twenty-two women were identified by the Virginia Regional Spinal Cord Injury System by formal and informal follow up procedures. A 5-page questionnaire was 
used to gather the data by personal or telephone interview. Supplemental information was obtained from several of the patients' hospital records. We have found the Frankel classification ${ }^{5}$ useful in this study. Frankel classification A refers to a complete loss of motor and sensory function below the level of injury. Frankel classification $\mathrm{B}$ refers to partially preserved sensation below the level of injury. Frankel classification $\mathrm{C}$ refers to preserved, but not useful, motor function below the level of injury. Frankel classification D refers to retained useful motor and sensory function below the level of injury. Frankel classification E refers to patients with normal motor and sensory function but who may have abnormal reflexes.

The level of injury has been defined in the 1990 revision of the Standards for Neurological Classification of Spinal Injury Patients $^{6}$ as the 'lowest normal neurological segment with both motor and sensory function'.

\section{Results}

There were 33 pregnancies in 22 women, 30 newborns, and 3 abortions of which 2 were induced and one spontaneous (Table I). The etiology of SCI was as follows: 16 resulted from motor vehicle accidents (MVA), one a motorcycle accident; 3 from gunshot wounds (GSW); one from diving; one from skydiving; and one from a fall from a horse (Table II). The level of injury was cervical in 11 and thoracic in 11 (Table II). Eight of the

Table I Summary of pregnancies and outcomes

\begin{tabular}{lr}
\hline Pregnancies & 33 \\
Babies & 30 \\
Abortions & 3 \\
$\quad$ Induced & 2 \\
$\quad$ Spontaneous & 1 \\
Fetal birth weights $(\mathrm{g})$ & \\
$\quad 1600$ & 1 \\
$2160,2240,2300$ & 3 \\
$2500-3000$ & 11 \\
$3001-3500$ & 8 \\
$3501-4000$ & 6 \\
4760 & 1 \\
\hline
\end{tabular}

cervical injuries were incomplete and 9 of the thoracic injuries were complete (Table II).

There was a decreasing average age at delivery if the patients were grouped by (1) 1950-1970 dates of injury and (2) those injured in the 1980s. The average age at delivery decreased from 28.2 years to 22.6 years. Also, the average of the above 2 groups for time between injury and delivery decreased from 7.5 years to 4.0 years (Table III).

Ultrasound was performed increasingly in the 1970 s $(37 \%), 1980$ s $(59 \%)$ and 1990 s $(100 \%)$. Amniocentesis was utilized 4 times or $13 \%$.

Autonomic hyperreflexia $(\mathrm{AH})$ was experienced in 9 of the 16 pregnancies of patients whose injury level was above T6 (56\%; Table IV). These 16 pregnancies occurred in 12 patients, with 7 patients experiencing $\mathrm{AH}(58 \%), 2$ for the first time.

The patients were noted to have increased blood pressure during routine checks in the later stages of labor, except for one case, a C7 complete SCI who developed $\mathrm{AH}$ during cesarean section (CS) without anesthesia. This patient received intravenous diazepam to control apparent spinal cord seizures. Six patients received epidural anesthesia, which was successful in controlling the $\mathrm{AH}$.

One patient, whose $\mathrm{AH}$ was controlled during labor by epidural anesthesia, experienced postpartum $\mathrm{AH}$ associated with afterbirth pains for a total of 5 days. The epidural catheter was left in place and used to treat the $\mathrm{AH}$ during this period.

Another patient, a C7 complete SCI, had two grand mal seizures during labor without anesthesia, probably triggered by her severe $\mathrm{AH}$. The seizures required intravenous diazepam for control, which also reduced the AH.

Finally, although most of the patients who experienced $\mathrm{AH}$ had motor complete injuries (Frankel A or B), 2 of the patients with Frankel D injuries also had AH. One of these, a C3 SCI, had $\mathrm{AH}$ when she delivered without anesthesia. The other, a C6 SCI, had AH controlled by epidural anesthesia. None of the patients with SCI at $\mathrm{T} 7$ or below experienced $\mathrm{AH}$.

There were 5 SC deliveries for which 
Table II SCI identification code, etiology, neurological level, Frankel classification and age at injury

\begin{tabular}{lcccc}
\hline Patient ID code & Etiology & $\begin{array}{c}\text { Neurological } \\
\text { level }\end{array}$ & $\begin{array}{c}\text { Frankel } \\
\text { classification }\end{array}$ & $\begin{array}{c}\text { Age at } \\
\text { injury }\end{array}$ \\
\hline Cervical SCI & MVA & C2 & D & 21 \\
A & GSW & C3 & D & 23 \\
B & GSW & C4 & B & 28 \\
C & Sky diving & C5 & B & 24 \\
D & MVA & C5 & D & 18 \\
E & MVA & C5 & A & 25 \\
F & Diving & C6 & B & 18 \\
G & MVA & C6 & D & 16 \\
H & MVA & C6 & D & 15 \\
I & MVA & C7 & A & 19 \\
J & MVA & C7 & A & 16 \\
K & & & & \\
Thoracic SCI & MVA & T2 & A & 16 \\
L & MVA & T4 & A & 18 \\
M & MVA & T7 & A & 18 \\
N & MVA & T8 & A & 25 \\
O & MVA & T10 & B & 16 \\
P & MVA & T10 & A & 17 \\
Q & MVA & T10 & A & 20 \\
R & MVA & T10 & A & 27 \\
S & MVA & T12 & A & 22 \\
T & Fall from horse & T12 & A & 29 \\
V & GSW & T12 & B & 15 \\
\hline
\end{tabular}

MVA = motor vehicle accident; GSW = gunshot wound

general anesthesia was used. One of the deliveries occurred in a $\mathrm{C} 4$ incomplete $\mathrm{SCI}$ Frankel B classification patient who did not experience or have a history of $\mathrm{AH}$. The CS was performed due to a breech presentation (Table IV).

\section{Anesthesia}

Epidural anesthesia was selected for 9 deliveries. General anesthesia was used for 5 deliveries. Local anesthesia was given 4 times for episiotomy and repair. No anesthesia was given to 12 patients (Table IV).

\section{Delivery}

Induction of labor was performed with Pitocin in 11 patients and one by rupturing membranes.

Cesarean sections were performed 13 times $(43 \%)$. Of these, 5 were repeat CS. Eight CS were for the following reasons: 2 lack of progress; 2 transverse presentation; one breech presentation; one antepartum bleeding not requiring transfusion; one mother's request and tubal ligation: one started labor one day after spinal fusion, which was 2 weeks post MVA-SCI. This last patient had 3 pregnancies, all delivered by CS and general anesthetic. She had a T7 complete SCI, Frankel A (Table IV).

Prematurity occurred in 4 infants whose birth weight was less than $2500 \mathrm{~g}$ (Table I). The smallest weighed $1600 \mathrm{~g}$ and was born at home, unattended, after a precipitate labor. The mother had been in bed for 2 months for pre-eclampsia as a complete T10 paraplegic. She did not have any signs or symptoms that she recognized as labor until a bloody show, ruptured membranes and delivery. Two other infants weighed 2150 and $2250 \mathrm{~g}$; fetal age had been determined by ultrasound. In addition, one had amniocentesis and both were born by CS. The 
Table III Date/level of injury, Frankel classification, date of delivery, interval in years from injury to delivery and age at delivery

\begin{tabular}{|c|c|c|c|c|}
\hline $\begin{array}{l}\text { Date/level } \\
\text { of injury }\end{array}$ & $\begin{array}{c}\text { Frankel } \\
\text { classification }\end{array}$ & $\begin{array}{l}\text { Date of } \\
\text { delivery }\end{array}$ & $\begin{array}{l}\text { Interval in years } \\
\text { from injury to } \\
\text { delivery }\end{array}$ & $\begin{array}{l}\text { Age at } \\
\text { delivery }\end{array}$ \\
\hline $1950 \mathrm{~s}-\mathrm{T} 10$ & A & 1956 & 6 & 23 \\
\hline $1971-\mathrm{C} 7$ & A & 1984 & 13 & 32 \\
\hline $1972-\mathrm{T} 4$ & A & 1983 & 11 & 29 \\
\hline $1972-\mathrm{C} 3$ & $\mathrm{D}$ & 1978 & 6 & 29 \\
\hline $1973-\mathrm{C} 5$ & B & 1972 & 9 & 33 \\
\hline 1974-Т10 & A & 1977 & 3 & 30 \\
\hline 1974-Т10 & B & 1983 & 9 & 31 \\
\hline 1974-T12 & A & 1983 & 9 & 25 \\
\hline $1976-\mathrm{C} 6$ & $\mathrm{D}$ & 1983 & 7 & 27 \\
\hline 1976-Т10 & A & 1980 & 4 & 19 \\
\hline 1976-T7 & A & 1976 & 0 & 18 \\
\hline $1978-\mathrm{T} 8$ & A & 1987 & 9 & 34 \\
\hline 1979-Т12 & B & 1990 & 11 & 26 \\
\hline \multirow[t]{2}{*}{$1979-\mathrm{C} 4$} & B & 1986 & 7 & 35 \\
\hline & & & Average $=7.5$ & Average $=28.2$ \\
\hline $1982-\mathrm{C} 6$ & B & 1989 & 7 & 25 \\
\hline 1983-T10 & A & 1984 & 1 & 20 \\
\hline $1983-\mathrm{C} 5$ & $\mathrm{D}$ & 1988 & 5 & 23 \\
\hline 1984-C6 & D & 1989 & 5 & 21 \\
\hline $1984-\mathrm{T} 2$ & A & 1990 & 6 & 22 \\
\hline $1984-\mathrm{C} 2$ & D & 1989 & 5 & 26 \\
\hline 1987-C7 & B & 1990 & 3 & 19 \\
\hline \multirow[t]{2}{*}{$1988-\mathrm{C} 5$} & A & 1988 & 0 & 25 \\
\hline & & & Average $=4.0$ & Average $=22.6$ \\
\hline
\end{tabular}

fourth premature infant weighed $2300 \mathrm{~g}$ and was born after a vigorous 2-hour labor as a double footling breech. This mother has a tracheostomy and is a C2 Frankel D quadriplegic requiring a ventilator at night for sleep apnea. The infant had an APGAR of 1 at $1 \mathrm{~min} 7$ at $5 \mathrm{~min}$ and 9 at $10 \mathrm{~min}$. During labor, one mother was given ritodrine for 3 days and another terbutaline for 10 days for tocolysis without adverse effects, and had term babies weighing 3600 and $4000 \mathrm{~g}$, respectively.

\section{Complications}

Urinary tract infections (UTI) were related to urine bladder management. The pregnancies were divided into 4 groups of bladder/urine management. The first group consisted of those using retention catheter and ileal conduit, the second group used intermittent catheterization (ICP); the third group used the Crede method; and the fourth group did not use a catheter or Crede, and was called 'normal void'. All patients using retention catheters during pregnancy ( 5 urethral and 2 suprapubic) had at least one symptomatic UTI during pregnancy; the one patient with an ileal conduit (loop) also had a UTI (Table V). The other 3 groups had UTI as follows: ICP 6 pregnancies, 50\% with UTI (Table VI); Crede 6 pregnancies, $17 \%$ with UTI (Table VII); normal void 10 pregnancies, $40 \%$ with UTI (Table VIII). By combining the no-catheter patients (Tables VII and VIII), we found only $31 \%$ had UTI; by combining ICP plus Foley catheter groups, we found $77 \%$ had UTI (Tables V and VI).

Bladder stones developed in association with retention catheter use in 2 patients.

Pressure sores occurred in 2 patients. One 
Table IV Patient identification code, level of injury, Frankel classification, delivery method, autonomic hyperreflexia and anesthesia

\begin{tabular}{|c|c|c|c|c|}
\hline $\begin{array}{l}\text { Patient ID code/ } \\
\text { level of injury }\end{array}$ & $\begin{array}{c}\text { Frankel } \\
\text { classification }\end{array}$ & $\begin{array}{l}\text { Delivery } \\
\text { route }\end{array}$ & $\begin{array}{c}\text { Autonomic } \\
\text { hyperreflexia }\end{array}$ & Anesthesia \\
\hline \multicolumn{5}{|l|}{ T4 and above } \\
\hline $\mathrm{A}-\mathrm{C} 2$ & $\mathrm{D}$ & Vaginal (breech) & No & No \\
\hline $\mathrm{B}-\mathrm{C} 3$ & $\mathrm{D}$ & Vaginal & Yes & No \\
\hline $\mathrm{C}-\mathrm{C} 4$ & B & $\mathrm{CS}$, breech & No & General \\
\hline $\mathrm{D}-\mathrm{C} 5$ & $\mathrm{~B}$ & CS, transverse & Yes & Epidural \\
\hline D-C5 & B & CS, repeat & Yes & Epidural \\
\hline $\mathrm{E}-\mathrm{C} 5$ & $\mathrm{D}$ & CS, overdue & No & Epidural \\
\hline $\mathrm{E}-\mathrm{C} 5$ & $\mathrm{D}$ & CS, repeat & No & Epidural \\
\hline $\mathrm{F}-\mathrm{C} 5$ & A & Vaginal & No & Epidural \\
\hline $\mathrm{G}-\mathrm{C} 6$ & B & CS, dystocia & Yes & Epidural \\
\hline $\mathrm{H}-\mathrm{C} 6$ & $\mathrm{D}$ & Vaginal & Yes & Epidural \\
\hline $\mathrm{I}-\mathrm{C} 6$ & $\mathrm{D}$ & Vaginal & No & Local \\
\hline I-C6 & $\mathrm{D}$ & Vaginal & No & No \\
\hline $\mathrm{J}-\mathrm{C} 7$ & $\mathrm{~A}$ & Vaginal & Yes & No \\
\hline $\mathrm{K}-\mathrm{C} 7$ & A & $\mathrm{CS}$, bleeding & Yes & No \\
\hline M-T4 & A & $\mathrm{CS}$, transverse & Yes & Epidural \\
\hline $\mathrm{M}-\mathrm{T} 4$ & A & $\mathrm{CS}$, repeat & Yes & Epidural \\
\hline \multicolumn{5}{|l|}{$T 7$ and below } \\
\hline $\mathrm{N}-\mathrm{T} 7$ & A & CS (1 day post fusion) & No & General \\
\hline $\mathrm{N}-\mathrm{T} 7$ & A & $\mathrm{CS}$, repeat & No & General \\
\hline $\mathrm{N}-\mathrm{T} 7$ & A & CS, repeat & No & General \\
\hline $\mathrm{O}-\mathrm{T} 8$ & B & Vaginal & No & None \\
\hline $\mathrm{P}-\mathrm{T} 10$ & B & Vaginal & No & Local \\
\hline $\mathrm{P}-\mathrm{T} 10$ & B & Vaginal & No & Local \\
\hline $\mathrm{P}-\mathrm{T} 10$ & B & Vaginal & No & Local \\
\hline Q-T10 & A & Vaginal & No & No \\
\hline $\mathrm{R}-\mathrm{T} 10$ & A & Vaginal & No & No \\
\hline S-T10 & B & Vaginal & No & No \\
\hline $\mathrm{S}-\mathrm{T} 10$ & B & Vaginal & No & No \\
\hline $\mathrm{T}-\mathrm{T} 12$ & $\mathrm{~A}$ & Vaginal & No & No \\
\hline U-T12 & A & Vaginal & No & No \\
\hline $\mathrm{V}-\mathrm{T} 12$ & A & CS (mother's choice) & No & General \\
\hline
\end{tabular}

Table $\mathbf{V}$ Foley catheter bladder management with patient identification code, level of injury, Frankel classification, incidence of infections and use of antibiotics per pregnancy

\begin{tabular}{llccc}
\hline $\begin{array}{l}\text { Patient ID code/ } \\
\text { level of injury }\end{array}$ & Method & $\begin{array}{c}\text { Frankel } \\
\text { classification }\end{array}$ & Infections & Antiobiotics \\
\hline B-C3 & Foley catheter & D & Yes & Yes \\
C-C4 & Foley catheter & B & Yes & Yes \\
F-C5 & Foley catheter & A & Yes & Yes \\
G-C6 & Foley catheter & B & Yes & Yes \\
K-C7 & Foley catheter & A & Yes & Yes \\
M-T4 & Suprapubic catheter & A & Yes & Yes \\
M-T4 & Suprapubic catheter & A & Yes & Yes \\
R-T10 & Ileal conduit & A & Yes & Yes \\
\hline
\end{tabular}


Table VI ICP bladder management with patient identification code, level of injury, Frankel classification, incidence of infections and use of antibiotics per pregnancy

\begin{tabular}{lcccl}
\hline $\begin{array}{l}\text { Patient } \\
\text { ID code }\end{array}$ & $\begin{array}{c}\text { Level } \\
\text { of injury }\end{array}$ & $\begin{array}{c}\text { Frankel } \\
\text { classification }\end{array}$ & Infections & Antibiotics \\
\hline A & C2 & D & Yes 1 X & PM + Yes \\
I & C6 & D & Yes 1 X & Yes \\
I & C6 & D & 0 & No \\
J & C7 & A & 0 & No \\
O & T8 & A & 2 X & Yes \\
U & T12 & A & 0 & PM \\
\hline
\end{tabular}

$\mathrm{PM}=$ prophylactic (Macrodantin $50 \mathrm{mg}$ b.i.d.) given throughout pregnancy.

Table VII Crede bladder management with patient identification code, level of injury, Frankel classification, incidence of infections and use of antibiotics per pregnancy

\begin{tabular}{lcccl}
\hline $\begin{array}{l}\text { Patient } \\
\text { ID code }\end{array}$ & $\begin{array}{c}\text { Level } \\
\text { of injury }\end{array}$ & $\begin{array}{c}\text { Frankel } \\
\text { classification }\end{array}$ & Infections & Antibiotics \\
\hline D & C5 & B & 0 & PM \\
D & C5 & B & 0 & PM \\
Q & T10 & A & 0 & No \\
S & T10 & A & 0 & No \\
S & T10 & A & 1 & PM + Yes \\
T & T12 & A & 0 & No \\
\hline
\end{tabular}

$\mathrm{PM}=$ prophylactic (Macrodantin $50 \mathrm{mg}$ b.i.d.) given throughout pregnancy.

Table VIII Normal void bladder management with patient identification code, level of injury, Frankel classification, incidence of infections and use of antibiotics per pregnancy

\begin{tabular}{lcccc}
\hline $\begin{array}{l}\text { Patient } \\
\text { ID code }\end{array}$ & $\begin{array}{c}\text { Level } \\
\text { of injury }\end{array}$ & $\begin{array}{c}\text { Frankel } \\
\text { classification }\end{array}$ & Infections & Antibiotics \\
\hline E & C5 & D & No 0 & No \\
E & C5 & D & Yes 2 & Yes \\
H & C6 & D & No 0 & PM \\
N & C7 & A & No 0 & No \\
N & C7 & A & No 0 & No \\
N & C7 & A & Yes 1 & Yes \\
P & T10 & B & No 0 & Yes + PM \\
P & T10 & B & Yes 1 & No \\
P & T10 & B & No 0 & Yes \\
V & T12 & B & Yes 1 & \\
\hline
\end{tabular}

$\mathrm{PM}=$ prophylactic (Macrodantin $50 \mathrm{mg}$ b.i.d.) given throughout pregnancy.

patient sat in her wheelchair in the lotus position until she had necrosis of soft tissues extending into the ankle joint. The resulting infection required intravenous (IV) antibiotics for one week in the hospital, followed by bilateral below-knee amputations. The other patient developed a sacral sore in hospital associated with incontinence and a pilonidal sinus tract cyst. Surgery was performed successfully 2 months later.

One patient abraded the skin during a transfer to the bathroom. This became infected as a cellulitis, required hospital admission and several days of IV antibiotics. 
One patient experienced influenza and a complication of pneumonia and required hospital care with antibiotics for a week.

A summary of complications is given in table IX.

\section{Special problems}

One patient was 8 months pregnant at the time of her MVA-SCI. She was fused 2 weeks later and went into labor within $24 \mathrm{~h}$ delivering a $2950 \mathrm{~g}$ healthy newborn by CS and using a general anesthetic. This fusion was broken down subsequent to a second pregnancy and several reported falls from her wheelchair.

One patient was having her third post SCI vaginal delivery when the fetus developed a cardiac irregularity. The umbilical cord was wrapped around his neck. When corrected, the newborn was fine.

Another patient developed mastitis 3 weeks after delivery. Six weeks after delivery increasing leg spasms were associated with a UTI. Two months later the patient was found to have a disc infection requiring anterior discectomy, posterior fusion and 6 weeks of IV antibiotics.

One patient was 5 months pregnant at the time of her MVA-C5 injury (complete). She required a tracheotomy and ventilation for over a month after injury. She did not leave the hospital until 2 weeks after delivery, over 3 months after her accident and SCI. Amniocentesis was performed to determine fetal pulmonary maturity. She received Pitocin for induction and epidural anesthesia was used for delivery. There was no $\mathrm{AH}$

Table IX Summary of antepartum, intrapartum and postpartum complications

A Antepartum complications

1 Autonomic hyperreflexia-8

2 A minimum of one or more symptomatic urinary tract infections during pregnancy -16 pregnancies: 2 required hospitalization and IV antibiotics

3 Pressure sores -1 with sepsis, led to bilateral below-knee amputations

4 Bladder stones - 2: both patients had Foley catheters

5 Pneumonia-1 associated with influenza: patient is a C6 Frankel D SCI, hospitalized and given IV antibiotics

6 Cellulitis (from abrasion)-1: septic, required IV antibiotics in hospital

7 Premature labor-3: 2 infants were delivered full term

8 Bleeding (not transfused) -2

9 Pre-eclampsia (delivered prematurely) -1

10 Anemia (hematocrit 21)-1, although several patients had mild anemias

11 Diabetes mellitus - 1: insulin used for last 7 weeks of pregnancy

12 Delayed onset of labor-treated by CS

B Intrapartum complications

1 Autonomic hyperreflexia-9

2 Cesarean sections-13: 5 were repeat CS

3 Abnormal presentation: transverse -2 breech -2 , one delivered as a double footling (vaginally)

4 Failure to progress -5

5 Medical inductions-11: pitocin used

6 Surgical induction (ruptured membranes) -1

C Postpartum complications

1 Intermittent $\mathrm{AH}-1$ : epidural catheter left in and used for 5 days, one patient had $\mathrm{AH}$ with after-pains for 6 weeks; no treatment given

2 UTI-3: 2 patients required IV antibiotics, all followed use of short term Foley catheter for labor and delivery and postpartum for $2-3$ days

3 Infected pilonidal cyst -1 : developed infection in hospital, required surgery 2 months later

4 Episiotomy dehiscence -1 : absorbable suture used

5 Uterine atony $-1: 2$ blood transfusions required 
and the baby weighed $2975 \mathrm{~g}$. She developed a UTI postpartum.

Newborns were all reported healthy and normal, with the exception of one infant having an undescended testicle which was repaired 2 years later.

Costs

Cost of maternity care was covered by private insurance in $60 \%$ of deliveries (18/30); Medicare/Medicaid covered 23\% of deliveries (7/30); Champus and cash payment accounted for 2 each and one patient had no funding.

\section{Discussion}

This study found increasing numbers of SCI women becoming pregnant and having healthy infants. The average age at delivery has decreased by almost 6 years in the last decade. In the last three decades obstetrical and SCI care have made significant advances. These advances should lead to changes in the management of SCI women.

\section{Fertility}

Fertility is not significantly altered post SCI in women of childbearing age. Menses may be altered but, 3-9 months post SCI, should return to the pre-SCI status. ${ }^{2.7}$ Contraception can be practised with the use of a variety of options such as condoms, diaphragms, jellies, foams, the rhythm method and coitus interruptus. Success rates are similar to that in the able bodied population. ${ }^{8}$ The concerns about the use of oral contraceptives in SCI women, however are higher than in the able bodied population. Oral contraceptives have increased risks for those who smoke or are over 35 years of age and those who have a history of thromboembolism. SCI women are at greater risk for thrombophlebitis and pulmonary embolism than the able bodied population. In a recently published study $\mathrm{McCluer}^{9}$ reports that in a group of $227 \mathrm{SCI}$ women $77(34 \%)$ were quadriplegic and $153(67 \%)$ were paraplegic. Of these, $76 \%$ of paraplegics and $56 \%$ of quadriplegics were sexually active post injury. Six percent of the 70 women using birth control pills developed an episode of thrombophlebitis.

\section{Pregnancy}

Once a decision to become pregnant is made, physician consultation is needed to plan for a proper and safe course of action. Medications commonly used for spasticity and spasms are baclofen and diazepam. Sudden withdrawal of baclofen can cause seizures. ${ }^{10}$ This medication must be tapered over a few days. ${ }^{11}$ Anticonvulsant medication such as phenytoin ${ }^{12}$ or carbamazepine ${ }^{13}$ must also be tapered over several days rather than suddenly being discontinued. Diazepam has known addictive properties and newborn infants have been observed to experience withdrawal symptoms after birth when the mother has been on therapeutic dosages. ${ }^{14}$ There is a reported increase in infant cleft palate in patients taking diazepam $^{15-17}$ and phenytoin. ${ }^{18}$ No human studies have been reported on the use of baclofen in pregnancy. In animal studies, there was an increased incidence of omphaloceles and failure in development of some ossification sites in offspring. ${ }^{10}$ Many other drugs, including some antibiotics, have an increased risk to the fetus. Current drug information must be reviewed to make the best judgement if a specific drug use is warranted in pregnancy. ${ }^{19,20}$

When performing radiologic (xray) procedures during pregnancy caution is recommended in order to prevent or minimize fetal exposure to irradiation. Alcohol use and smoking are well known to cause significant adverse effects on the fetus. These risks are not known to be greater in the SCI population of pregnant women than in able bodied women, but use of these agents must be managed situationally.

If $\mathrm{AH}$ has been experienced or is likely to occur, the pregnancy is considered high risk and the patient should consider delivery in a tertiary care center. Consultation with the anesthesiologist prior to labor is recommended. In addition, the obstetrician, urologist and primary physician should be familiar with AH management. Hospital nursing staff will need to be aware of the patient's routine SCI care needs. The patient's home 
SCI care plan should be continued except for those procedures necessary to and in preparation for delivery. Many patients indicated that the hospital staff did not listen to them with regard to their disability and how they manage outside of the hospital. The patient will have the most informed knowledge concerning her skin care routine and bowel and bladder management.

As the 7th month arrives (28th week), the cervix will need to be monitored regularly for effacement or dilatation, as often as 1-2 times a week. The patient will need to be taught how to detect uterine contractions in the event she does not feel pain (T10 or above complete SCI). If labor begins, or the cervix dilates and is effaced, early hospital admission must be considered.

In this study, prematurity occurred in 4 infants. Fetal prematurity and premature labor are reported as increased in SCI women, especially in patients with upper thoracic and cervical SCI. ${ }^{1,8,21}$ This has resulted in the recommendation for early hospital admission and/or careful regular monitoring of the cervix for effacement, dilatation or progression of labor. This may be especially important for first-pregnancy expectant mothers who do not have normal painful sensations during the first stage of labor. These patients need to be taught how to determine whether they are in labor by other methods. A plan that allows time to get to the appropriate hospital on time and before delivery is essential.

Fetal age determination by ultrasound during pregnancy is possible with a high degree of accuracy when performed in the second trimester. Biparietal head measurements are the gold standard. ${ }^{22-25}$ Ultrasound is also helpful in determining placental location, fetal position and number, some fetal anomalies and occasionally sex..$^{25}$ Amniocentesis is used primarily for genetic determinations but is occasionally indicated to verify pulmonary maturity. ${ }^{26}$ Steroids can be useful to hasten pulmonary maturation ${ }^{26}$ and tocolytic agents are occasionally appropriate in postponing labor in selected patients if there are no contraindications. ${ }^{27}$ The lecithin/sphingomyelin ratio is determined as an index of fetal pulmonary maturation.
Fetal injuries occurring at the time of the mother's SCI have also been reported by Goller and Paeslack on 1979. ${ }^{21}$

\section{Labor}

The greatest risk to SCI women, in addition to the pregnancy risks found in the able bodied population, is for those patients who develop $\mathrm{AH}$ during labor and delivery. Recognition of this syndrome is necessary to prevent a potential catastrophe. It is essential that the patient and her physician recognize this syndrome and know that it can occur (and will if it has in the past).

$\mathrm{AH}$ or autonomic dysreflexia was described in part by Bowlby in 1890, later by Head and Riddoch in $1917 .{ }^{28}$ The complete syndrome was described by Guttmann and Whittridge in $1974 .{ }^{29}$ Kewalramani $^{30}$ and Erickson $^{31}$ provided excellent reviews and the basis for understanding this syndrome. AH usually occurs in patients with SCI at T6 and above but has been reported in one patient who had a T10 level injury. ${ }^{32}$ The entire syndrome of symptoms and signs is not always present. In addition to headache, frequent findings include excessive sweating, splotchy rash, pilomotor erection (usually above the level of injury), facial flush, congested nasal passages, paroxysmal hypertension and bradycardia. During labor the onset of this syndrome is intermittently timed with uterine contractions. Between contractions, the signs and symptoms usually subside. This is to some degree dependent upon the frequency of contractions. At least 2 patients have been reported who developed severe hypertension without recognition or adequate treatment of $\mathrm{AH}$ and subsequently developed intraventricular hemorrhage, one fatal. ${ }^{33,34}$ One patient was thought to have had pre-eclampsia and was so treated with inadequate response.

The onset of $\mathrm{AH}$ may be associated with any noxious stimulus below the level of the SCI: a full bladder, an enema or bowel movement, uterine contractions, changing a catheter, or vaginal or rectal examinations. Blood pressure monitoring in labor and delivery must be frequent, at least at each contraction until a pattern is established. Continuous maternal and fetal electronic 
monitoring would be ideal. Treatment requires differentiation from pre-eclampsia, and recognition that the symptoms and findings are intermittent and initiated by uterine contractions during labor. Blood pressure elevation occurs most often during the time of the stimulus (uterine contraction or other) and is followed very soon by a severe headache or other previously described signs.

Control of dangerously high blood pressure can be accomplished in most patients with a continuous epidural anesthetic for labor and delivery. Medications can be used and may be successful with continuous, careful monitoring of the patient and blood pressure. Nifedipine (10-20 mg chew and swallow) may be used for a short term and rapid response. This may be repeated in 20-30 minutes if blood pressure remains elevated. Nifedipine can also be used prior to any procedure known to cause $\mathrm{AH}$ by the patient's history. ${ }^{35}$ IV hydralazine or trimetaphan can also be used to control elevated blood pressure when closely monitored and adjusted. Use of inhaled amyl nitrite to control the hypertension of $\mathrm{AH}$ has been described by Verduyn. ${ }^{8}$

Many authors recommend epidural anesthesia for labor and delivery of SCI women. ${ }^{36-39}$ The first report of epidural anesthesia used in a quadriplegic to control $\mathrm{AH}$ during labor and vaginal delivery was by Stirt in $1979 .{ }^{36}$ Nath $^{40}$ in 1979 reported a 36 year old T6 paraplegic in whom spinal anesthesia was needed to supplement epidural anesthesia to control $\mathrm{AH}$ adequately. The patient was delivered by CS after which the mother and $3290 \mathrm{~g}$ infant were fine. CS requires a level of anesthesia above T10, which is adequate for control of $\mathrm{AH}$. CS with spinal anesthesia is effective for control of $\mathrm{AH}$ but has administration problems over a long labor period. General anesthesia is used effectively for CS but has similar problems to spinal anesthesia regarding administration over a period of time to control AH during labor. Additionally, if given there are added fetal risks. Selective local anesthesia or omission of anesthesia may be appropriate. T10 level complete SCI women have no sensation of pain during labor and delivery. Patients with complete
SCI at T12 feel uterine contractions, cervical effacement and dilatation. ${ }^{2}$ Secondstage labor sensation, discomfort and pain are transmitted through the lumbosacral roots. Incomplete SCI will usually require at least local anesthesia for episiotomy and repair.

\section{Delivery}

CS has been used increasingly in the able bodied to reduce fetal mortality, and maternal and fetal morbidity. The increased frequency of CS births is correlated with increased use of electronic fetal heart monitoring, primarily during labor. There has been an approximately 8-fold increase in CS from the 1950 s to the late 1980 s in the United States. This increase is from about $3 \%$ to over $24 \%$ of all deliveries. ${ }^{41}$ The identified causes include: (1) failure to progress in labor (30\%); (2) fetal distress $(15 \%)$; (3) repeat CS $(30 \%)$; (4) breech presentation $(15 \%) .{ }^{42}$ Other less common causes are eclampsia, prolapsed umbilical cord, transverse presentation, abruptio placenta and placenta previa. Currently, maternal mortality is reported to be about 4 times higher in CS deliveries than in vaginal deliveries $(9.8$ vs 40 per 100,000$) .{ }^{42}$ CS may be used to terminate and control AH. Most pregnant SCI women who have medically uncontrolled $\mathrm{AH}$ during labor will require either epidural, spinal or general anesthesia to control the severe hypertension during delivery. $2,43,44$

Outlet forceps are often required in vaginal deliveries of SCI patients to assist in the second stage of labor due to weak abdominal muscle strength.

Episiotomy closure should be with non absorbable sutures. Denervated areas do not absorb the cat gut-type sutures and often lead to sterile abscess or wound dehiscence. $^{1}$

\section{Other complications}

In this group of pregnant patients UTI was the most common complication. The urinary tract status must be known and, if needed, a urological consultation must be 
obtained for guidance. As this study indicates, fewer infections are present in patients who do not use or require a catheter. The retention catheter patients had a symptomatic UTI in $100 \%$ of the pregnancies. The patients without retention catheters all had significant incontinence as they came closer to term. One patient put in a Foley catheter when she had a symptomatic UTI and indicated that it allowed her more time for the care of her infant. Two others had a postpartum symptomatic UTI after a temporary Foley catheter was used for 2-4 days peripartum. One patient developed a skin breakdown in hospital associated with incontinence postpartum.

A comprehensive review of urological management in SCI patients was published by Stover in $1989 .{ }^{45} \mathrm{~A}$ recent paper addresses urological outcomes in female SCI patients. ${ }^{46}$

Pressure sores continue to be a major problem for SCI patients and their physicians. The ideal rehabilitation program with the ideal patient may result in an outcome that allows for prevention of pressure sores. Although there has been excellent progress made in early recognition and treatment and, when required, newer more successful major surgical repairs can be made, this problem continues to be with us.

In the Virginia Regional SCI System a course is taught to SCI women (and their significant other) in parenting from a wheelchair with a disability. Previous experiences of mothers and staff have been well received and helpful to future parents. The scope of this paper does not permit discussion of other important issues for the female that becomes SCI.

Excellent resources are now available written by both SCI patients and experienced clinicians.

Elle Friedman Becker, a T6 complete paraplegic, has written a book addressing female sexuality following SCI. ${ }^{47}$ This book provides excellent physical, medical and psychosocial information; in addition, 19 women were interviewed who discuss their experiences and adjustments to SCI. Barry Rabin PhD has written a paperback book that addresses sexual adjustment after SCI. ${ }^{48}$

The most recent comprehensive text edited by JFJ Leyson has just become available (1991). It is an excellent resource for those of us who care for patients with SCI. ${ }^{49}$

\section{Conclusions}

SCI women are increasingly becoming pregnant at a younger age and delivering healthy infants. $\mathrm{AH}$ is present in over $50 \%$ of T6 and above SCI patients. This has been underdiagnosed and often treated inappropriately or not at all. SCI patients who have or may have AH (T6 and above) must be considered as having high-risk pregnancies and referred for care and delivery to tertiary medical centers. Epidural anesthesia is preferred and effective for most patients with AH during labor and delivery. In preparation for labor and delivery, ultrasound and, on occasions, amniocentesis are needed to protect the fetus from premature birth. This is especially true in this population of patients who have a higher than normal incidence of CS.

\section{Acknowledgements}

This study was supported in part by grant G008535193 from the National Institute on Disability and Rehabilitation Research to the Virginia Regional Spinal Cord Injury Center of the University of Virginia, Department of Orthopedics, Charlottesville, Virginia, and the Virginia Spinal Cord Injury System, Fisherville, Virginia.

\section{References}

1 Robertson DNS, Guttmann L (1963) The paraplegic patient in pregnancy and labor. Proc Royal Soc Med 56: 381-387.

2 Berard EJJ (1989) The sexuality of spinal cord injured women, physiology and pathophysiology: a review. Paraplegia 27: 99-112.

3 Wanner WB, Rageth CJ, Zach GA (1987) Pregnancy and autonomic hyperreflexia in spinal cord lesions. Paraplegia 25: 482-490. 
4 Ohry A, Peleg D, Goldman J, David A, Rozin R (1978) Sexual function, pregnancy and delivery in spinal cord injured women. Gynecol Obstet Invest 9: 281-291.

5 Frankel HL, Hancock DO, Hyslop G et al (1969) The value of postural reductions in the initial management of closed injuries of the spine with paraplegia and tetraplegia. Paraplegia 7: 179-192.

6 Donovan WH, Maynard FM, McCluer S et al (1990) Standards for Neurological Classification of Spinal Injury Patients. American spinal Injury Association, Chicago, Il.

7 Comarr AE (1966) Observation on menstruation and pregnancy among female spinal cord injury patients. Paraplegia 3: 263-271.

8 Verduyn WH (1986) Spinal cord injured women, pregnancy and delivery. Paraplegia 24: 231-240.

9 McCluer S (1991) Reproductive aspects of spinal cord injury in females. In: Leyson JFJ, editor. Sexual Rehabilitation of the Spinal Cord Injured Patient. Humana Press, Clifton, NJ: 189-190.

10 Terrence DV, Fromm GH (1981) Complications of baclofen withdrawal. Arch Neur 38: 588-589.

11 Barnharter ER, editor (1991) Physician's Desk Reference. 45th ed. Medical Economics, Oradell, NJ: 1009.

12 Ibid, 1642.

13 Ibid, 1016.

14 Rementeria JL, Bhatt K (1977) Withdrawal symptoms in neonates from intrauterine exposure to diazepam. J Pediatr 90: 123-126.

15 Saxen I (1975) Associations between oral clefts and drugs taken during pregnancy. Int J Epidemiology 4 : $37-44$.

16 Saxen I (1975) Epidemiology of cleft lip and palate. Br J Prev Soc Med 29: 103-110.

17 Safra JM, Oakley GP (1975) Association between cleft lip with or without cleft palate and neonate exposure to diazepam. Lancet ii: 478-480.

18 Barnharter ER, editor (1991) Physician Desk Reference. 45th ed Medical Economics, Oradell, NJ: 1641.

19 Kuemmerle HP, Brendel K, editors (1984) Clinical Pharmacology in Pregnancy. Thieme Stratton, Inc, New York.

20 Niebyl JR (1988) Drug Use in Pregnancy. Lea and Febiger, Philadelphia.

21 Goller H, Paeslack V (1972) Pregnancy damage and birth complications in children of paraplegic women. Paraplegia 10: 213-240

22 Kramer MS, McLean FH, Boyd ME, Usher RH (1988) The validity of gestational age estimation by menstrual dating in term preterm, and postterm gestations. JAMA 260: 3306-3308.

23 Persson PH, Weldner BM (1986) Reliability of ultrasound fetometry in estimating gestational age in the second trimester. Acta Obstet Gynecol 65: 481-483.

24 Campbell S, Warsof SL, Little D, Cooper JC (1985) Routine ultrasound screening for the prediction of gestational age. Obstet Gynecol 65: 613-620.

25 Manning FA (1989) General principles and application of ultrasound. In: Creasy RK, Resnick R editors. Maternal and Fetal Medicine. WB Saunders, Philadelphia: 195-253.

26 Jobe A (1989) Amniotic fluid tests of fetal lung maturity. In: Creasy RK, Resnick R, editors. Maternal and Fetal Medicine. WB Saunders, Philadelphia: 426-427.

27 Creasy RK (1989) Preterm labor and delivery. In: Creasy RK, Resnick R editors. Maternal and Fetal Medicine. WB Saunders, Philadelphia: 189-193.

28 Head H, Riddoch G (1917) Autonomic bladder excessive sweating and some reflex conditions in gross injuries of spinal cord. Brain 46: 188-263.

29 Guttmann L, Whitteridge D (1947) Effects of bladder distension on autonomic mechanism after spinal cord injuries. Brain 70: $361-404$.

30 Kewalramani LS (1980) Autonomic dysreflexia in traumatic myelopathy. Am J Phys Med 59: 1-21.

31 Erickson RP (1980) Autonomic hyperreflexia: pathophysiology and medical management. Arch Phys Med Rehabil 61: 431-440.

32 Gimovsky ML, Ojeda A, Ozaki R, Zerne S (1985) Management of autonomic hyperreflexia associated with a low spinal cord lesion. Am J Obstet Gynecol 153: 223-224.

33 Abouleish E (1980) Hypertension in a paraplegic parturient. Anesthesiology 53: 349.

34 McGregor JA, Meeuwsen J (1985) Autonomic hyperreflexia: a mortal danger for spinal cord-damaged women in labor. Am J Obstet Gynecol 151: 330-333.

35 Lindan R, Lehler E, Freehafer A, Lyons AM, Coletta H (1986) Further experience with nifedipine in the treatment of autonomic dysreflexia. ASIA Bulletin 4: 10-15

36 Stirt JA, Marco A, Conklin KA (1979) Obstetric anesthesia for a quadriplegic patient with autonomic hyperreflexia. Anesthesiology 51: 560-562.

37 Watson DW, Downey GO (1980) Epidural anesthesia for labor and delivery of twins of a paraplegic mother. Anethesiology 52: 259-261.

38 Ravindran RS, Cummins DF, Smith IE (1981) Experience with the use of nitroprusside and subsequent epidural analgesia in a pregnant quadriplegic patient. Anesth Anal 63: 61-63.

39 Brian J, Clark RB, Quirk JG (1988) Autonomic hyperreflexia, cesarean section and anesthesia. J Reproductive Med 33: 645-649.

40 Nath M, Vivian J, Cherny W (1979) Autonomic hyperreflexia in pregnancy and labor: a case report $A m J$ Obstet Gynecol 134: 390-392.

41 Stafford RS (1990) Alternative strategies for controlling rising cesarean section rates. JAMA 263: 683-687. 
42 Bowes WA (1989) Normal and abnormal labor. In: Creasy RK, Resnick R, editors. Fetal and Maternal medicine. 2nd ed. WB Saunders, Philadelphia: 530-531.

43 Committee on Obstetrics (1990) Maternal and Fetal Medicine: Management of Labor and Delivery for Patients with Spinal Cord Injury. ACOG Committee Opinion No 83. American College of Obstetricians and Gynecologists, Washington, DC.

44 Porter SS (1988) Anesthetic management of the patient with spinal cord injury. Kansas Med Nov.: 299-304.

45 Stover SL, Lloyd K, Waites KB, Jackson AB (1989) Urinary tract infection in spinal cord injury. Arch Phys Med Rehab 70: 47-54.

46 Timoney AG, Shaw PJR (1990) Urological outcome in female patients with spinal cord injury: the effectiveness of intermittent catheterization. Paraplegia 28: 556-563.

47 Becker EF (1978) Female Sexuality Following Spinal Cord Injury. Cheever Pub Co., Bloomington, Il.

48 Rabin BJ (1980) The Sensuous Wheeler. Available from author, Suite 353, 5595 E 7th St, Long Beach, CA 90804, USA.

49 Leyson JFJ, editor (1991) Sexual Rehabilitation of the Spinal Cord Injured Patient. Humana Press, Clifton, NJ. 